\title{
30. International Vienna Motor Symposium 7-8 May 2009 - Report presented on the occasion of the International Congress PTNSS on Combustion Engines 2009 in Opole
}

\author{
30 Międzynarodowe Wiedeńskie Sympozjum Motoryzacyjne 7-8 maja 2009 \\ - sprawozdanie wygłoszone z okazji Międzynarodowego Kongresu Silnikowego \\ PTNSS 2009 w Opolu
}

\section{About the Symposium}

For more than 30 years the Austrian Society of Automotive Engineers has been organizing the Vienna Motor Symposium which is one of the most important networking events for specialists in engine and vehicle research and production worldwide. At this symposium which took place in $7-8^{\text {th }}$ May this year, leading experts from the automotive industry, presented the latest findings related to the engine and powertrain research, design and development. Over 1000 participants took part in lectures, presentations and several discussions concerning the most important questions related to the present and future development of the means of transport, drivetrains, energy sources and energy conversion issues, not to mention the pollution generated by transport.

In Figure 1 you can see the entrance to the Symposium in the former residence of the Austrian Emperors, who ruled for more than 600 years and it is now the traditional venue of the Symposium. Figure 2 shows the Opening Session in the Hofburg Festsaal.

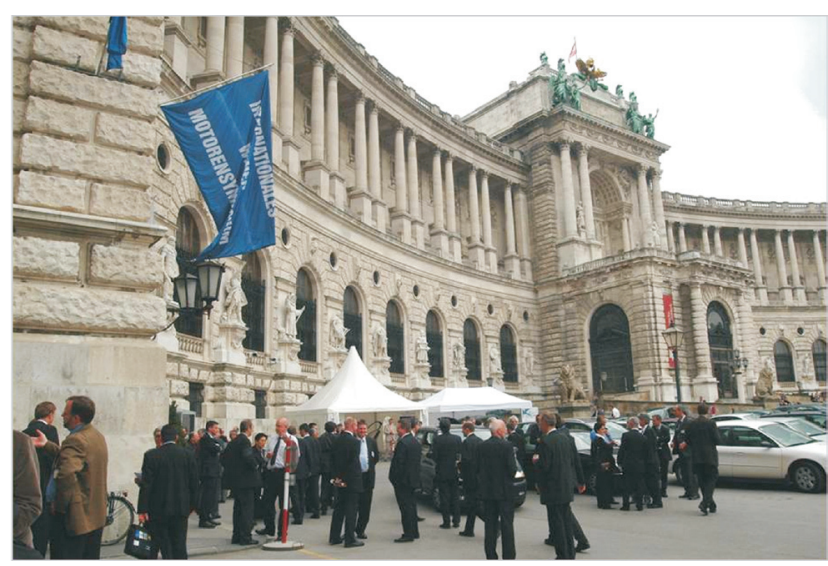

Fig. 1. Entrance to the Symposium in the Residence of Austrian Emperors Hofburg

This year two important general topics were addressed by our symposium:

- First - Comparison of Well-to-Wheel-Energy Efficiency of Different Vehicle Concepts

- Second - Will Hybrid Technology be the End of the Conventional Internal Combustion Engine?
It seems not possible to discuss all the presented lectures held on the Symposium this year. Only a few important presentations have been reported very briefly here.

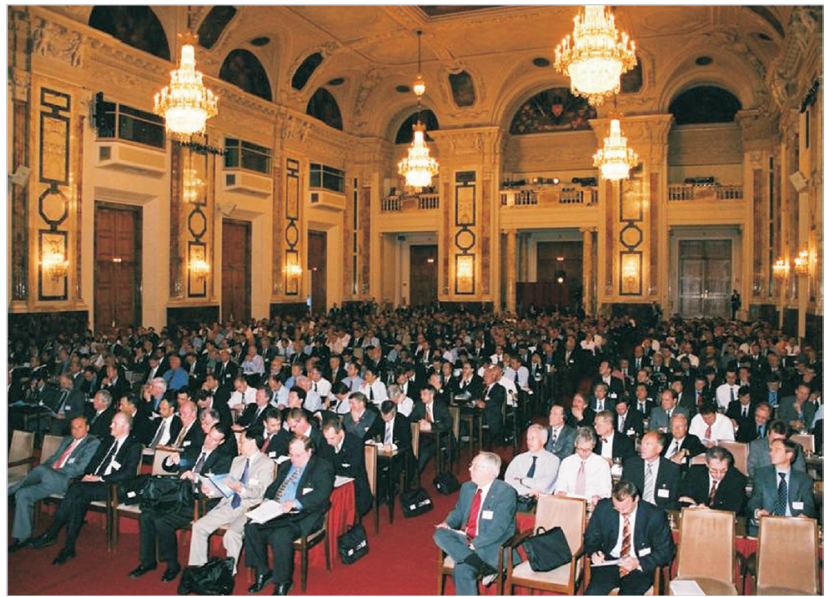

Fig. 2. The Opening Session in the Hofburg Festsaal

\section{Hybrid Technology and Powertrain Efficiency}

Will Hybrid Technology be the End of the Conventional Internal Combustion Engine?

by Mr. Koei Saga, Managing Officer of Toyota Corp.

The Author raised the following 4 points in his lecture:

1. How does hybrid technology change the conventional ICE?

- Hybrid technology drastically improves the fuel efficiency of ICE vehicles.

- Hybrid powertrain technology today relies strongly on ICE performance. Therefore, the ICE needs continuous improvement.

- It is possible that hybrid optimised ICEs become the standard, however, this will not change the further developments of ICEs towards better performance and efficiency.

2. The key to penetrate a technology is to improve performance from the viewpoint of customers, to offer a wide choice and to realize it for an affordable price. This is because:

- Winning market acceptance is crucial for any technology to survive

- It is a must to secure profitability in order to continue the development. 
3. Will Hybrid Technology be the end of the conventional ICE?

- Hybrid technology does not mean the end of the ICE, but extends the life of fossil fuel and, therefore, the use of the ICE.

- However, before full expansion, it needs further technological evolutions and cost reduction.

4. Will Hybrid Technology be the way towards the electric vehicles $(\mathrm{EV})$ ?

- If the battery performance does not dramatically improve, it is very hard for EVs to cover all 4-wheel cars.

- HV technology is applicable to all powertrains for conserving energy consumption.

- PHV gives the HV the possibility to use diverse energy sources.

\section{Comparison of Well-to-Wheel-Energy Efficiency of Dif-} ferent Vehicle Concepts

by Prof. Dr. B. Göschel, standing in for Dr. Herbert Demel, COO Magna Vehicle and Powertrain Group.

In the Author's opinion one essential factor for future vehicles will be the overall amount of energy a vehicle requires over its whole life cycle.

The well-to-wheel analysis describes how efficient the fuel cycle and the use phase of the vehicle are. In Figure 3 you can see a comparison of different fuels and drive options for a conventional vehicle, like Fiat Panda. On the left hand side, you see the energy demand, converted into gasoline equivalent in liters per $100 \mathrm{~km}$, for production and delivery of the fuel (gray bars) and for the use of the fuel over a distance of $150,000 \mathrm{~km}$. The bars on the right hand side show the $\mathrm{CO}_{2}$ equivalent in grams per $\mathrm{km}$. If we compare gasoline with natural gas, the latter shows a higher energy demand due to the compression, but emits less $\mathrm{CO}_{2}$ in total. For diesel, the energy and emission values are approx. 10\% lower than for gasoline.

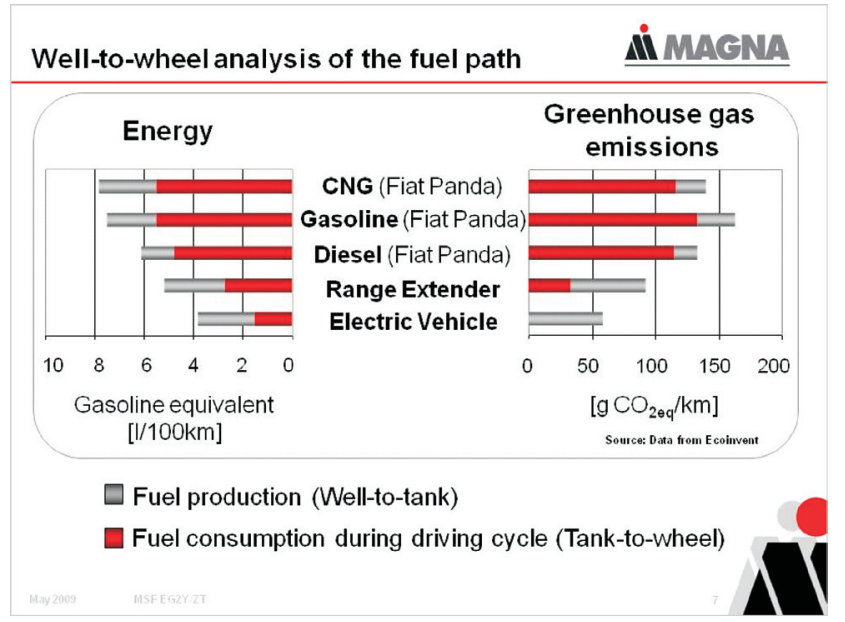

Fig. 3. Well-to-wheel analysis of the fuel path

In future, using electric vehicles could considerably reduce the energy demand as well as the emissions of $\mathrm{CO}_{2}$ as greenhouse gas in urban areas. This can be seen from the lowest bar, which is based on the Austrian electricity mix.
If a range extender is used based on an internal combustion engine, which charges the battery in regular operation, the values for energy demand and emissions are between a pure electric vehicle and a gasoline vehicle, as can be expected.

The cumulative energy demand of a vehicle, which includes the fuel cycle, the manufacturing of all materials, the vehicle assembly, the use phase and finally vehicle recycling, plays an increasingly important role. To calculate this cumulative energy demand, well-to-wheel studies are not sufficient. The entire life cycle needs to be taken into consideration. The following conclusions can be drawn:

- Light weight design helps reduce the energy demand considerably, but entails higher costs due to the materials used.

- Including recyclates and reintroducing already used materials into the vehicle production leads to huge energy and cost benefits.

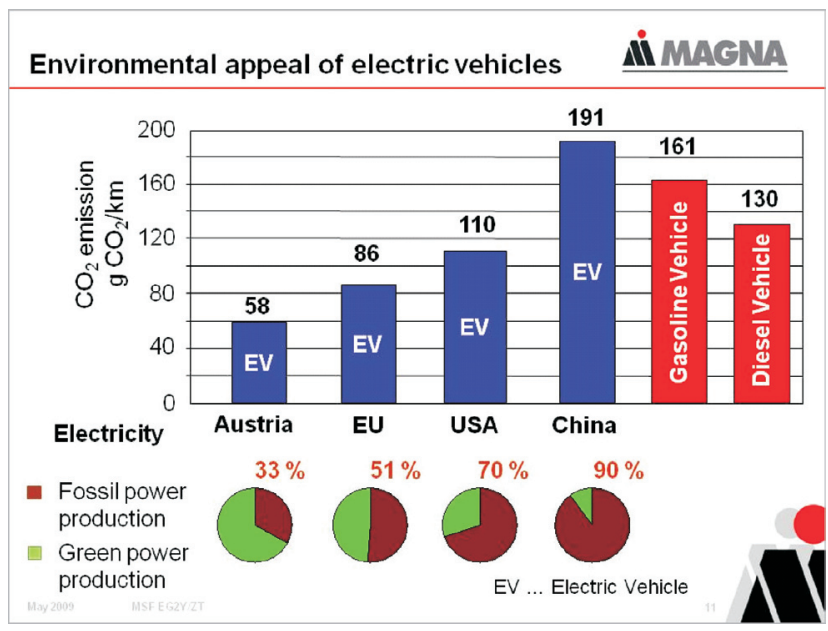

Fig. 4. Environmental appeal of electric vehicles [MAGNA]

If we assume that electric vehicles will dominate the future market, Fig. 4, we have to take into account that their $\mathrm{CO}_{2}$ emissions and other environmental effects heavily depend on the primary energy source used for electricity generation.

\section{New Engine Design}

Two presentations were delivered at the congress in which detailed technical highlights of the congress have been discussed.

The new 1.8 I Turbo DI Gasoline Engine for Passenger Cars of Mercedes-Benz

by Dipl.-Ing. Peter Lückert, Dipl.-Ing.Fritz Kreitmann, Dr.Norbert Merdes, Dr. Ralph Weller, Dipl.-Ing.Andreas Rehberger, Dr. Klaus Bruchner, Dipl.-Ing. Klaus Schwedler, Dipl.-Ing.Hermann Ottenbacher, Daimler AG.

The new M 271 evo described in this paper is representative of the ongoing efforts of Mercedes-Benz to implement its long-term downsizing concept for serial production passenger cars.

Key modifications include a changeover from port injection to homogeneous direct injection and substitution of the supercharger with a single-stage turbocharger fitted with wastegate. 


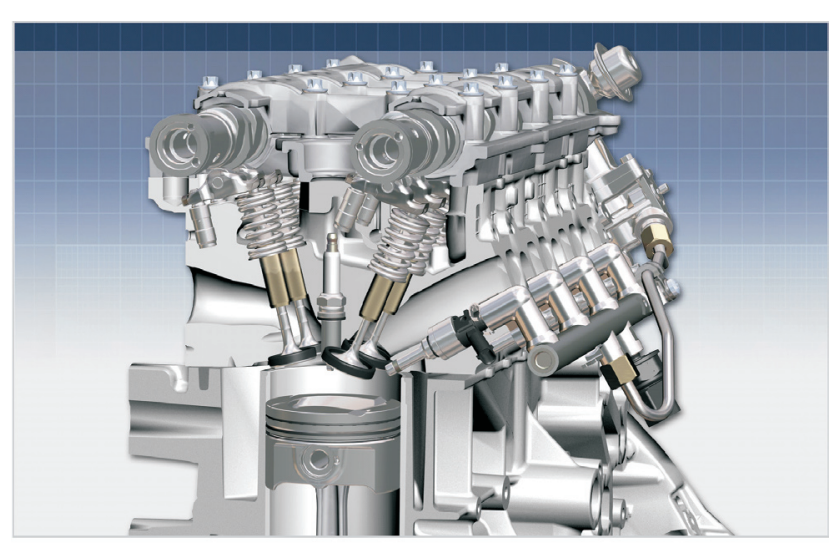

Fig. 5. Cylinder Head of the M 271 evo

The cylinder head of the M271 DE 18 LA is shaped differently than that of the predecessor engine due to direct injection. The intake ducts were adapted to the tumble characteristics required of the direct-injection engine.

The geometry of the four-valve design with two camshafts, adjusters and a central spark plug was carried over.

All versions of the engine feature a Lanchester balancer to compensate for second-order harmonic vibrations, Fig. 6. The cost-efficient concept was optimised to include "assembled" balancers based on the flat, one-piece aluminium-cast Lanchester balancer housing with sleeveless friction bearing of the predecessor engine.

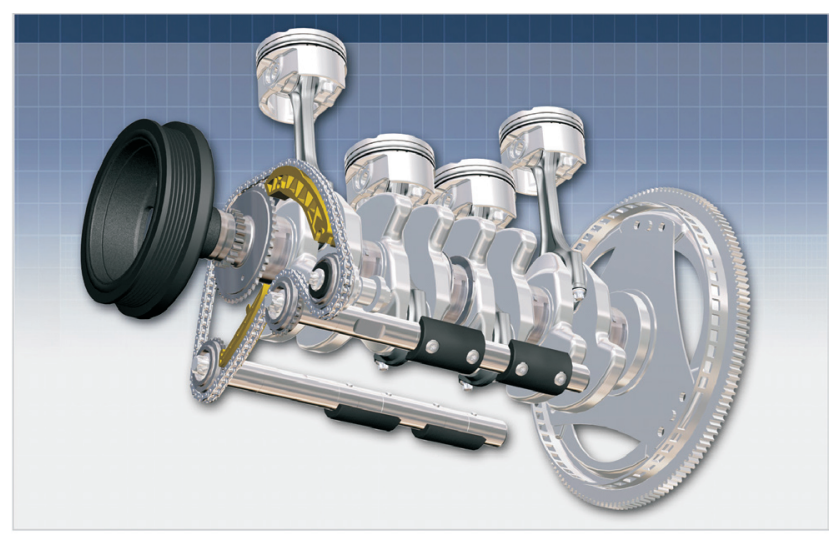

Fig. 6. Crank Assembly and Lanchester Balancer of the M271 evo
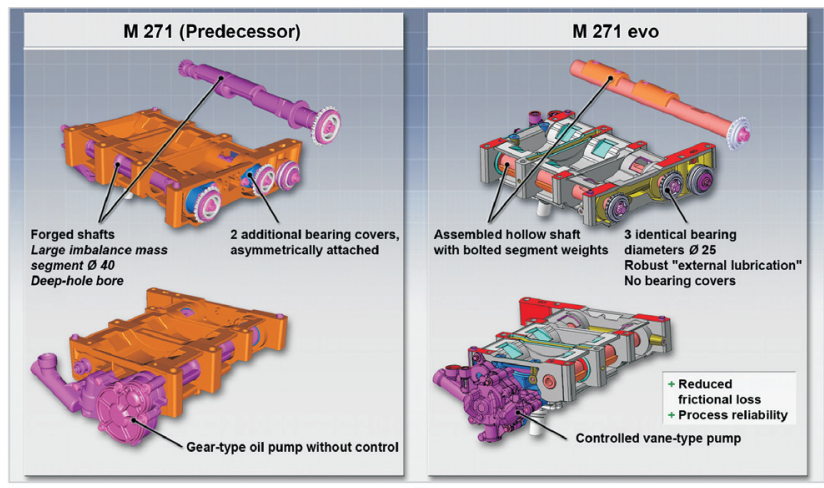

Fig. 7. Lanchester Assembly of the M271 evo and Predecessor Engine [DAIMLER]
To this end, two steel tubular shafts are inserted into the bearing tunnel of the balancer housing, Fig. 7. The imbalance mass segments are then bolted to the shafts. The abutting ends of the imbalance mass segments also serve as positioning and axial bearing points in the aluminium cast.

Each balancer shaft is supported by three slide bearings. This setup allows the bearing diameter in the vicinity of the imbalanced masses to be significantly smaller, thus greatly reducing friction.

Charging Concept of the M271 evo engine has been shown in Fig. 8. By carefully selecting the turbine and compressor combinations of the engine, it was possible to optimise performance under a variety of transient conditions. The different turbocharging options available differ only in the size of the compressor installed. In consequence, the turbine of the standard engine $(115 \mathrm{~kW})$ is used in the highoutput version ( $150 \mathrm{~kW})$ as well. Replacing the supercharger with a turbocharger is not only more efficient (less power input), but also reduces weight and engine noise.

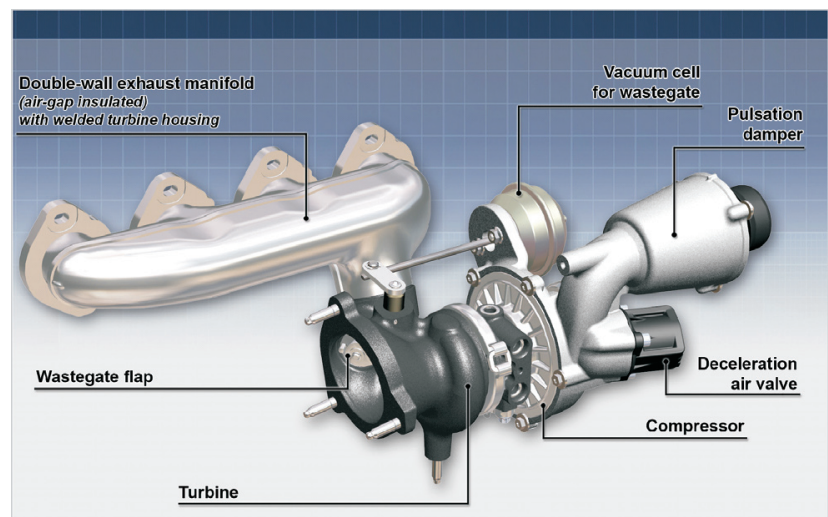

Fig. 8. Turbocharger of the M271 evo engine

Direct injection, Fig. 9, allows a higher compression compared to the conventional port injection of the predecessor engine and is thus more efficient. The turbocharged engine operates permanently in homogeneous mode; maximum fuel injection pressure is 140 bar. The high-pressure pump is a single-plunger pump. Fuel is delivered via a high-pressure rail to the injectors, which enter the combustion chamber at a $30^{\circ}$ angle.

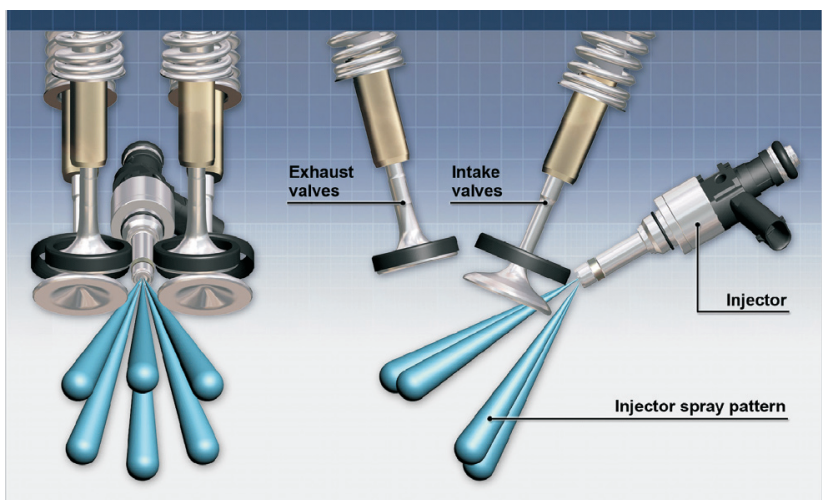

Fig. 9. Sample Spray Pattern of a Multi-Hole Solenoid Valve 
The nozzle jets which interact with the ever-changing fuel-air mixture and pressure inside the cylinders, are harmonized regarding the optimum penetration depth, the ability to homogeneous combustion and droplet size. These factors also directly impact the dilution of oil and soot build-up characteristics of the engine.

Multi-Hole solenoid valves were, therefore, studied to have a better understanding of the effects of different spray configurations and injection strategies. In the end, cycles characterized by high combustion stability with minimum exhaust and particulate emissions proved to be in line with the development goals.

\section{Innovative MAN Euro V Engine without Exhaust After- treatment}

by Dr.Wolfgang Held, Dipl.-Ing. Gottfried Raab, Prof. Dr. K.-V. Schaller, Dipl.-Ing. W. Gotre, Dipl.-Ing. H. Lehmann, Dipl.-Ing. H. Möller, Dipl.-Ing. W. Schröppel, MAN Nutzfahrzeuge.

The goal for the development of the Euro V EGR technology was to ensure a reliable compliance with the emission standards, and to possibly achieve this without aftertreatment.

An important component for achieving the goals is a regulated 2-stage supercharger with intercooler which enables a realization of a higher charge air pressures. This results in low-emission combustion and also requires less energy than single-stage supercharging. This, in turn has a direct positive effect on the fuel consumption. The injection pressure of the common rail fuel injection system was increased from 1600 to 1800 bar in order to achieve the goals. The exhaust gas recirculation rates were increased compared with the known Euro IV setting, which meant that it was necessary to improve the cooling performance of the external EGR cooler. A lambda control regulates the supply of cooled exhaust gas from the EGR cooler to the combustion process.

It was possible to achieve the set goals for different vehicle types in conjunction with a new cooling concept (low-temperature cooling concept).

The requirements of the Euro $\mathrm{V}$ emission regulations were reliably met with a downstream oxidation catalytic converter and the EEV (Enhanced Environmentally Vehicle) limits with a PM-Kat $\AA$ as a downstream filter.

Injection System used, Fig. 10, is the flexible BOSCH common rail system with 1800 bar. The required pressure is generated by a gear-driven high-pressure pump on the engine. Using solenoid-controlled injectors, this system supplies the combustion process with a demand based and freely selectable injection pressure that is independent of load and engine rpm.

The high injection pressure is also a precondition for the combustion process in order to reduce the higher particulate emission resulting from the increased EGR rates. These increased rates ensure that the $\mathrm{NO}_{\mathrm{x}}$ limits can be reached without any exhaust aftertreatment system. The multiple injection variability offered by a common rail system is exploited to optimise combustion by means of the preinjection, main injection and partially postinjection phases. This reduces raw particulate emissions and simultaneously minimizes fuel consumption.

The nozzle flow rate is reduced by smaller injection orifice cross-sections. This leads to finely bundled spray patterns, and the improved spray preparation also contributes to reducing the particulate raw emissions.

In the Two-stage Supercharger concept, a two-stage intercooled variant was chosen on the basis of simulations and tests on the engine test stand during prototype development as well as close collaboration with the supplier industry. A cooled two-stage supercharger requires less energy than a single-stage supercharger, and this has a direct positive effect on the fuel consumption of the engine.

In order to meet the Euro V/EEV regulations MAN has decided to use in the Exhaust Aftertreatment system an

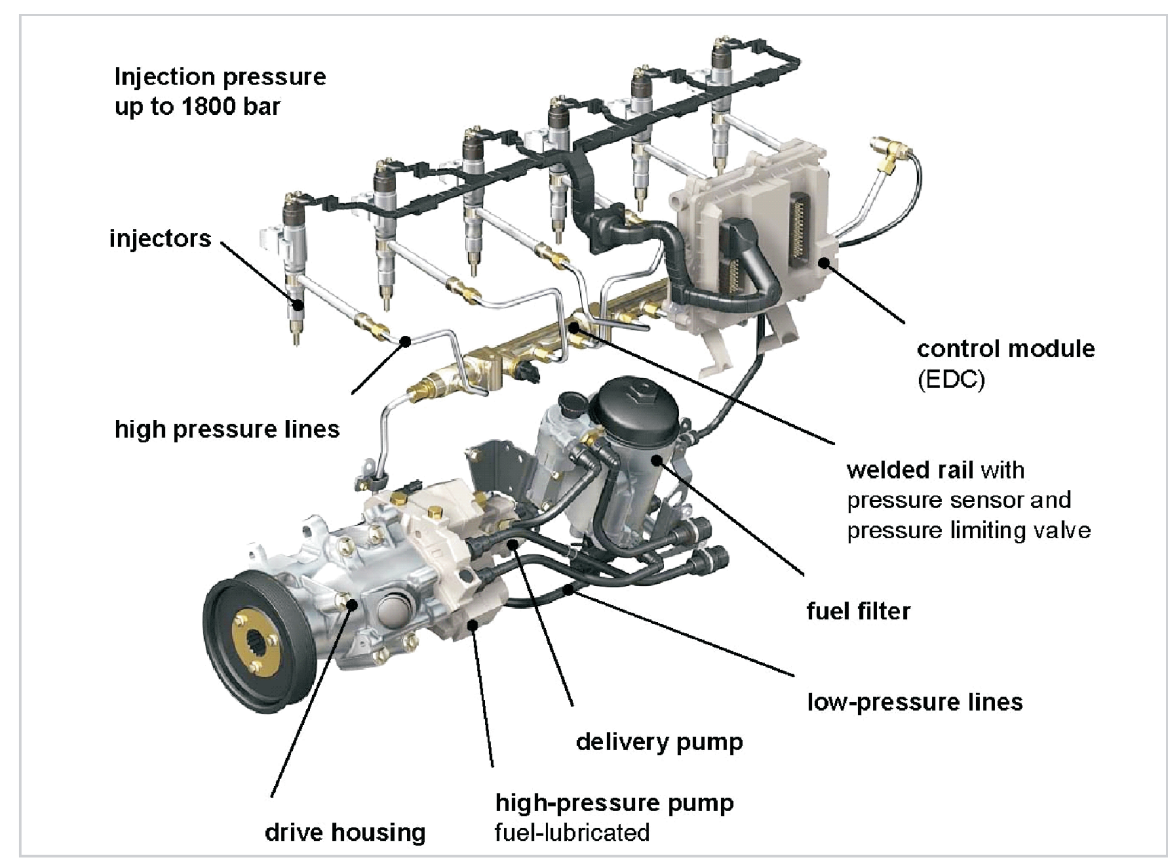

Fig. 10. Common rail injection system 1800 bar

oxidation catalyst to ensure a legally-compliant emission stability, Fig. 11. This catalytic converter type is characterized by low weight, little installation space requirement and freedom from maintenance. It is above all inexpensive and also appears to be suitable for Euro $\mathrm{V}$ for markets outside Europe. 


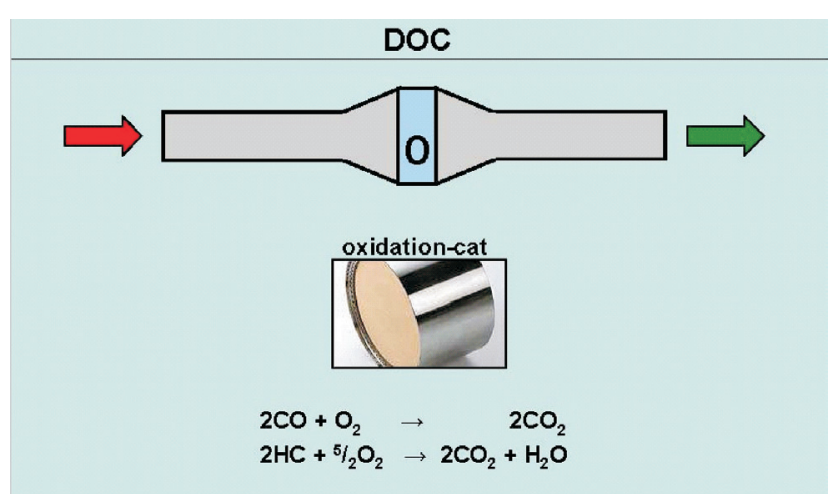

Fig. 11. Euro V solution with oxidation catalytic converter

Due to the low Euro V raw emissions, MAN can make use of the PM-Kat ${ }^{\circledR}$ technology already used in serial production for Euro IV in order to achieve compliance with the EEV limits in trucks, Fig. 12

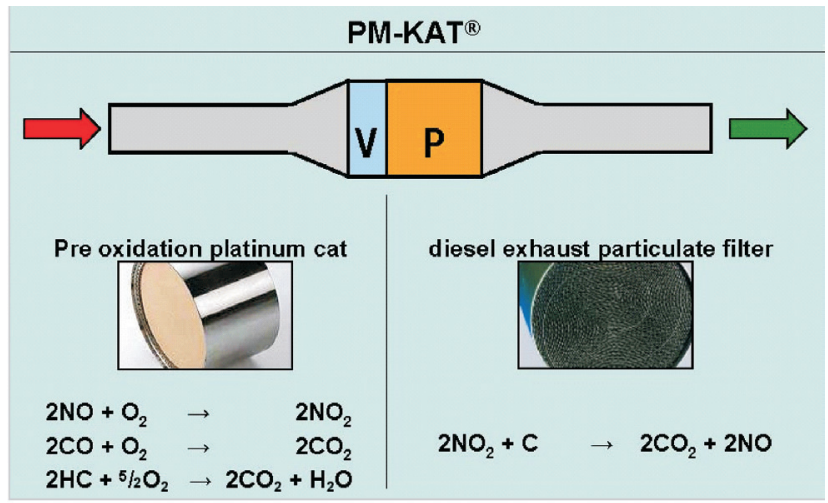

Fig. 12. EEV solution with PM-Kat ${ }^{\circledR}$

Low-temperature Cooling Concept. There are two main reasons why MAN decided to switch to a new cooling concept in conjunction with the Euro V EGR solution described here. Firstly, it was possible to increase the overall engine efficiency, especially due to the effective intercooling of the 2-stage supercharger. Secondly, the additional heat produced due to the higher EGR rates required for Euro V can be largely dissipated in existing vehicle concepts without any reduction in power or torque. The conventional direct air/charge air cooling system was left unchanged for low power ratings in the D08 series.

Test Results show the development of average fuel consumption through various scenarios based on the technology used at MAN, Fig. 13, whereby SCR technology is used only in the series D20/D26 and D2868 in serial production for Euro $\mathrm{V}$ and partially in EEV.

Outlook for Euro VI. The EGR technology described here in combination with further developed common rail injection systems represents the technical basis for offering a reliable and customer-orientated solution for the next emission standard Euro VI at an early stage.

\section{Literature}

[1] 30. Internationales Wiener Motorensymposium, VDI-Fortschrittbericht Reihe 12, Nr. 697, Vol.1, Vol. 2.

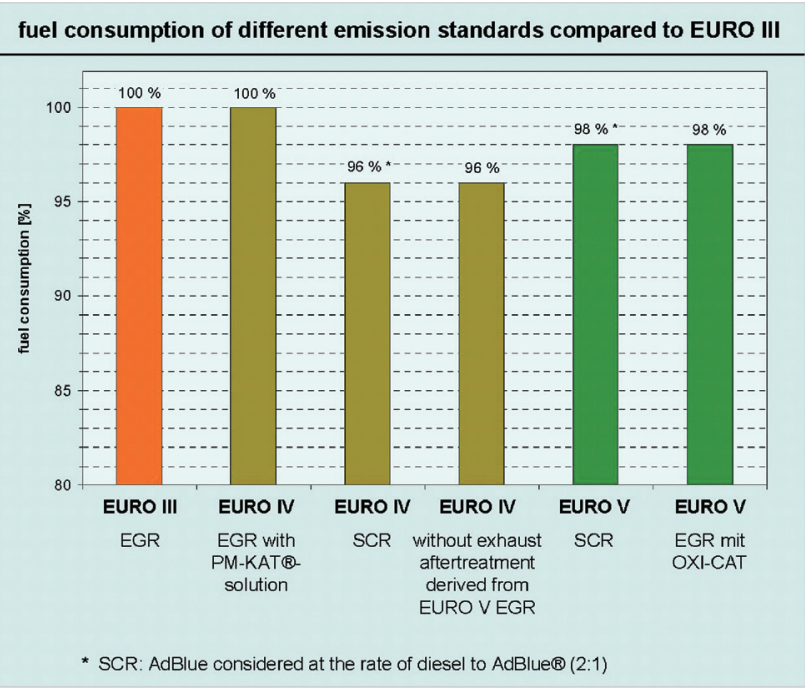

Fig. 13. Fuel consumption for the respective emission levels

If Euro VI serial-production solutions have to be available on the market for customers early on in order to obtain benefits relating to statutory road tolls, then this is currently possible only by making use of known and partially tested technology as shown in scenario 1 in Fig. 14.

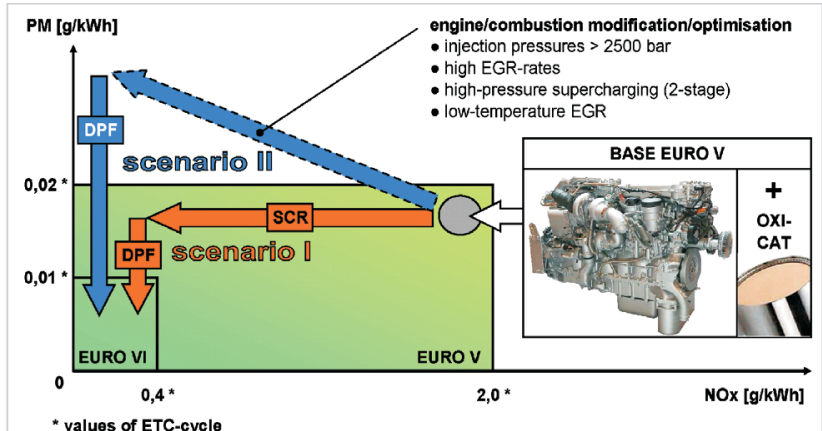

Fig. 14. Possible Euro VI scenarios

However, the described scenario I solution requires large installation space, reduces the payload and also results in a significant increase in system costs compared with Euro V. For this reason, development efforts will aim to find more economical solutions, as shown in possible scenario II.

The basis would again be the described Euro V AdBlue ${ }^{\circledR}$ free solution in conjunction with an improved 2-stage supercharger, an injection system $>2500$ bar and increased EGR rates. The solution would also include a 2-stage exhaust return cooler with low temperature cooling in combination with an improved vehicle cooling concept.

All details of the $30^{\text {th }}$ International Vienna Motor Symposium 2009 can be found in [1].

Prof. dr Hans Peter Lenz - Professor (retired) at the Technical University of Vienna, Austria, President of the Austrian Society of Automotive Engineers.

Prof. dr Hans Peter Lenz - emerytowany profesor Uniwersytetu Technicznego $w$ Wiedniu, przewodniczacy Austriackiego Stowarzyszenia Inżynierów Samochodowych. 